\title{
Características Clínicas de Doentes com COVID-19 num Internamento Dedicado do Hospital CUF Infante Santo: Série de Casos
}

\section{Clinical Features of Patients with COVID-19 Admitted to the Dedicated Service of CUF Infante Santo Hospital: A Series of Clinical Cases}

Fátima Grenho , Ana Lourenço², Sofia Ventura², Isabel Bogalho², Inês Bargiela², Catarina Santos Silva², Fábio Martins³, Luciano Hatchbach³, Nuno Lopes³, Alicia Prades², Maria João Gomes²

Autor Correspondente/Corresponding Author: Maria de Fátima Grenho [maria.grenho@jmellosaude.pt] Trav Castro, N 3, 1350-070, Lisboa, Portugal ORCID iD: 0000-0003-3028-3251

\section{RESUMO}

INTRODUÇÃO: A Rede CUF em 18 de março, disponibilizou o Hospital CUF Infante Santo (HCIS) como hospital de referência para os doentes com COVID-19 na área da grande Lisboa. O internamento do doente não crítico (IDNC) ficou a cargo de uma equipa médica dedicada (EMD) constituída por médicos do Cluster Tejo, sob coordenação da Medicina Interna. Este estudo reporta as principais características demográficas e clínicas da população internada no IDNC.

MATERIAL E MÉTODOS: Estudo retrospetivo analisando os doentes admitidos entre 27 de março e 7 de maio de 2020, no IDNC.

Os critérios para diagnóstico de COVID-19 basearam-se na confirmação laboratorial e/ou critérios de diagnóstico imagiológicos.

Excluíram-se da análise os doentes inicialmente suspeitos, mas cujo diagnóstico final encontrado foi outro.

Clinicamente, o doente não crítico foi definido como tendo um Modified Early Warning Score (MEWS) entre 0-2. Os dados foram coletados do processo clínico eletrónico e da base de dados criada para seguimento destes doentes. Apresentam-se as características demográicas, clínicas, exames complementares, terapêutica e resultados. RESULTADOS: Incluíram-se 44 doentes, média de idades 67 anos, 52,3\% homens. Divididos em grupos de acordo com a apresentação, com pneumonia em 75\%, os restantes com outra apresentação. Proveniência: domicílio 81,8\%, residência sénior $11,4 \%$ e outro hospital $8 \%$.

1. Serviço de Medicina Interna do Hospital CUF Infante Santo, Lisboa, Portugal. 2. Serviço de Atendimento Permanente do Hospital CUF Sintra, Sintra, Portugal. 3. Serviço de Atendimento Permanente do Hospital CUF Cascais, Cascais, Portugal. 
Fatores de risco para doença mais grave foram: Idade > 65 anos, 56,8\%, hipertensão arterial 59\%, doença respiratória crónica 15,9\%, obesidade 15,9\%, neoplasia ativa 13,6\%, diabetes 11,4\%, cardiopatia isquémica 11,4\%, insuficiência cardíaca 6,8\%, imunossupressão 6,8\%, com índice de comorbilidades de Charlson média de 3.6.

Agravamento clínico significativo com necessidade de escalar cuidados em três doentes (6,8\%), em dois (4,5\%) com ventilação mecânica invasiva, adicionalmente registado um óbito (2,3\%).

Demora média de internamento 10 dias, três (6,8\%) doentes foram transferidos para outro hospital e 40 (91\%) tiveram alta.

DISCUSSÃO: A casuística apresentada representa o primeiro grupo de doentes não críticos internados com COVID-19 na Rede CUF da Região de Lisboa.

Houve evolução e mortalidade intra-hospitalar abaixo do expectável para as características desta população, nomeadamente perante a presença de fatores de risco para doença mais grave e elevado índice de comorbilidades.

CONCLUSÃO: A interpretação dos resultados obtidos fica condicionada ao pequeno tamanho da amostra e às incertezas ainda existentes nesta nova doença.

PALAVRAS-CHAVE: COVID-19; Hospitalização; Infeções por Coronavírus; Pandemia; Pneumonia; SARS-CoV-2

\section{ABSTRACT}

INTRODUCTION: On $18^{\text {th }}$ March, CUF Group made the CUF Infante Santo Hospital (HCIS) available as the reference hospital for patients with COVID-19, in Lisbon area. The dedicated medical team (DMT) formed by doctors from the Tejo Cluster, under the coordination of Internal Medicine, was responsible for the non-critical patients' hospitalization (NCPH). This study reports the main demographic and clinical features of the admitted population.

MATERIAL AND METHODS: Retrospective study that analysis the features of NCPH, between 27 th March and $7^{\text {th }}$ May 2020. The diagnosis criteria for COVID-19 were based on laboratorial confirmation and/or imaging criteria.

The non-critical patient was defined as the patient that presented a Modified Early Warning Score (MEWS) between 0 and 2. Data was collected from patient's electronic clinical files and from the database created for the follow-up of these specific patients. Demographic and clinical features, complementary exams, therapy and results are presented in this paper.

RESULTS: We included 44 patients in the study, the mean age was 67 years old, 52.3\% were male. Patients were divided in groups according to the presence of Pneumonia (75\%) or not (25\%). Origin of the patients: home $81.8 \%$, nursing home $11.4 \%$ and other hospital $8 \%$.

Distribution according to risk factors of severe disease was: Age > 65 years old (56.8\%), high blood pressure (59\%), chronic respiratory disease (15.9\%), obesity (15.9\%), active cancer (13.6\%), diabetes (11.4\%), ischemic heart disease (11.4\%), heart failure (6.8\%), immunosuppression (6.8\%), with a mean score of Charlson's comorbidity index of 3.6. There was an increase on the severity of the clinical status of 3 patients (6.8\%) requiring an escalation of the clinical care, leading to 2 (4.5\%) patients requiring assisted ventilation and 1 death (2.3\%). Mean length of stay was 10 days, 3 (6.8\%) patients were transferred to another hospital and 40 (91\%) were discharged.

DISCUSSION: The sample presented in this study, represents the first group of non-critical patients admitted with COVID-19 into CUF Health care units in Lisbon region.

Taking into account the admitted population (namely risk factors for severe disease and an elevated comorbidity index), evolution and in-hospital mortality were better than expected.

CONCLUSION: Interpretation of these results is conditioned by the small size of this sample and the existing uncertainties with this new disease.

KEYWORDS: COVID-19; Coronavirus Infections; Hospitalization; Pandemics; Pneumonia; SARS-CoV-2

\section{INTRODUÇÃO}

Após identificação de um novo coronavírus pelas Autoridades de Saúde Chinesas, a Organização Mundial da Saúde (OMS) declarou em janeiro de 2020, a existência deste novo vírus (o sétimo dos coronavírus infetantes para o homem), mais tarde designado de SARS-CoV-2, responsável pela doença denominada COVID-19, com uma clínica variável, desde casos assintomáticos até expressão clínica grave como pneumonia viral potencialmente fatal. ${ }^{1}$

Os primeiros casos confirmados de doença por coronavírus 2019 (COVID-19) em Portugal ocorreram em 
02 de março de 2020 no Norte do país. Rapidamente se confirmaram novos casos a nível mundial, tendo sido declarada pela OMS disseminação pandémica em 9 de março. $^{2}$

Em Portugal, perante a proliferação de casos registados de contágio, o Presidente da República declarou a 18 de março, o "Estado de Emergência" com início a partir das 00:00 de 22 de março. ${ }^{3}$

Em 26 de março, entrou em vigor a fase de mitigação da pandemia da COVID-19, por determinação da Direção- Geral da Saúde (DGS), envolvendo todo o sistema de saúde, público e privado, estando nessa data já reportados, na região de Lisboa e Vale do Tejo, mais de 1000 casos confirmados. ${ }^{4}$

Perante uma situação de pandemia, foi necessário de modo célere organizar as unidades hospitalares para esta nova realidade.

Como resposta à situação nacional, a Rede CUF decidiu disponibilizar, a 18 de março, o Hospital CUF Infante Santo (HCIS) como hospital de referência para o diagnóstico e tratamento de doentes com infeção pelo novo coronavírus na região da grande Lisboa. ${ }^{5}$

Neste contexto, surgiu a necessidade de organizar as equipas médicas para o internamento dos doentes com COVID-19. Criaram-se três níveis de internamento consoante a gravidade do doente, ficando o internamento do doente não crítico (IDNC) sob coordenação da Medicina Interna.

A equipa médica dedicada (EMD) a este internamento integrou médicos do HCIS, do Hospital CUF Sintra e do
Hospital CUF Cascais e funcionou 24 horas, 7 dias por semana.

Houve um trabalho preparatório de formação da EMD para uma doença até então pouco conhecida, criando-se protocolos de avaliação e atuação, num tempo recorde de 1 semana, até ao internamento do primeiro doente com COVID-19, que aconteceu no dia 27 de março.

As recomendações para o tratamento farmacológico destes doentes foram baseadas em estudos in vitro de inibição da replicação viral de SARS-CoV-2; na evidência científica disponível à data, embora muito incompleta, inferida da experiência prévia de tratamento nos surtos de SARS-CoV-1 e MERS-CoV, além das orientações publicadas, para o tratamento da COVID-19, por entidades hospitalares e sociedades científicas nacionais e internacionais. ${ }^{6-11}$

Este estudo foi efetuado no HCIS e reporta as características demográficas, comorbilidades, resultados de exames complementares, terapêutica (baseada num protocolo interno), diagnósticos secundários e resultados dos doentes admitidos no IDNC.

\section{MATERIAL E MÉTODOS}

Estudo retrospetivo analisando todos os casos não críticos de COVID-19 admitidos no IDNC no período de 27 de março a 7 de maio de 2020.

O caso confirmado de COVID-19 foi definido laboratorialmente pela deteção de SARS-CoV-2 na zaragatoa nasofaríngea pelo teste de reverse-transcriptase-polymerase-chain-reaction (RT-PCR). ${ }^{12}$

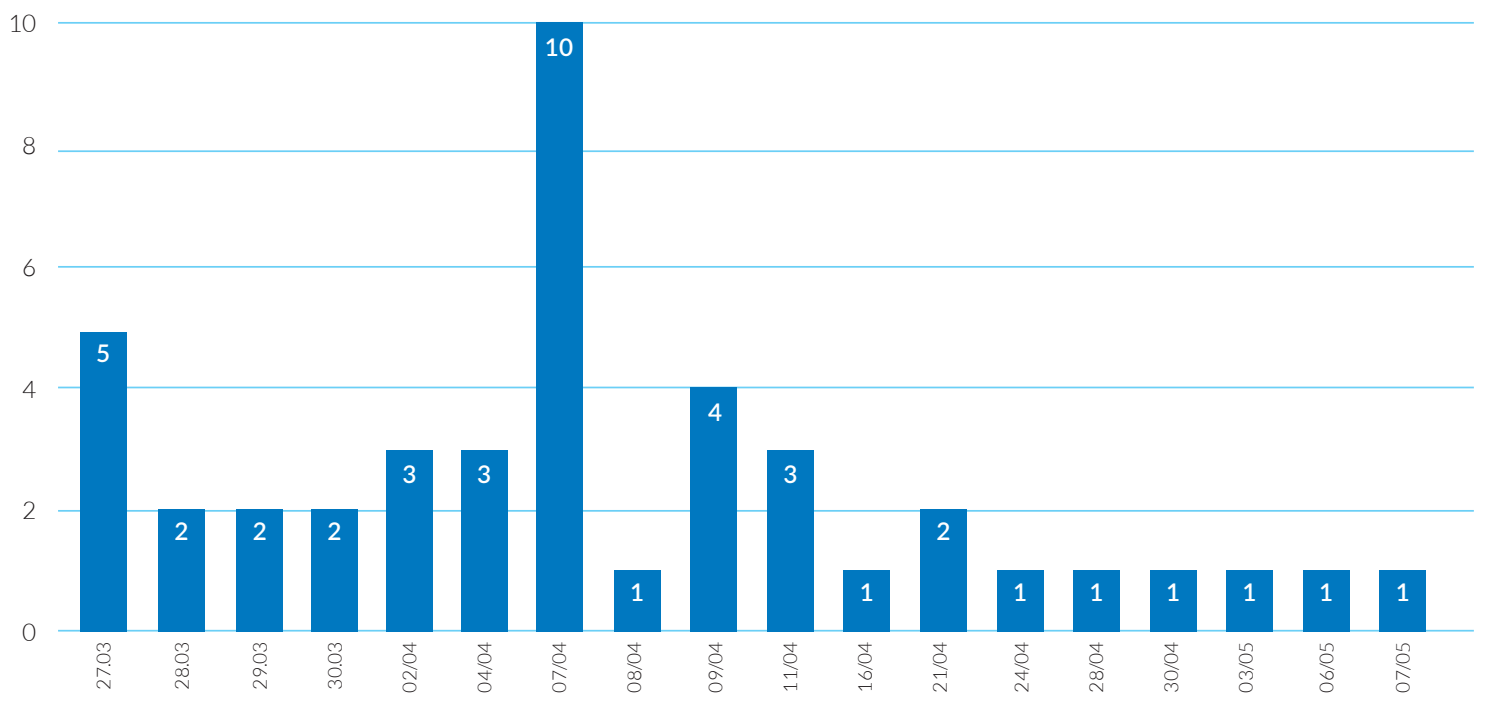


TABELA 1. Score de deterioração clínica.

\begin{tabular}{|c|c|c|c|c|c|c|c|}
\hline \multicolumn{8}{|l|}{ PARÂMETROS FISIOLÓGICOS } \\
\hline Sinais vitais & 3 & 2 & 1 & 0 & 1 & 2 & 3 \\
\hline Frequência respiratória (cpm) & --- & $<9$ & --- & $9-14$ & $15-20$ & $21-29$ & $\geq 30$ \\
\hline Frequência cardíaca (bpm) & --- & $\leq 40$ & $41-50$ & $51-100$ & $101-110$ & $111-129$ & $\geq 130$ \\
\hline Pressão arterial sistólica (mmHg) & $<70$ & $71-80$ & $81-100$ & 101-199 & & $\geq 200$ & \\
\hline Temperatura $\left({ }^{\circ} \mathrm{C}\right)$ & & $\leq 35$ & & $35,1-38,4$ & & $\geq 38,4$ & \\
\hline Resposta a estímulos & & & & Alerta & Reage à voz & Reage à dor & Não responsivo $(\mathrm{GCS}<9)$ \\
\hline
\end{tabular}

MEWS 0-2 - Doente estável com sintomas respiratórios e/ou sintomas sistémicos ligeiros a moderados.

MEWS 3-4 - Sintomas respiratórios e/ou sistémicos moderados a graves, clinicamente instável, mas não crítico.

MEWS $\geq 5$ - Sintomas graves/pneumonia grave.

Após avaliação nos Serviços de Atendimento Permanente (AP) da rede CUF, os doentes eram admitidos nos diferentes níveis de cuidados do HCIS de acordo com os critérios de internamento definidos. O IDNC recebeu doentes admitidos pelo AP do HCIS e transferidos do Hospital CUF Descobertas (HCD).

O doente não crítico foi definido clinicamente por ter um Modified Early Warning Score (MEWS) entre 0-2. Se score mantidamente acima de 3 , tinham indicação para referenciação para nível mais elevado de cuidados (Tabela 1). ${ }^{13}$

Foram admitidos no IDNC doentes com expressões clínicas diversas que se distribuíram por 4 grupos consoante a forma de apresentação clínica, laboratorial e imagiológica ${ }^{14-17}$ :

- Grupo I. Pneumonia e RT-PCR para SARS CoV-2 detetável;

- Grupo II. Pneumonia e suspeita COVID-19 por critérios clínicos e imagiológicos com RT-PCR para SARS-CoV-2 não detetável;

- Grupo III. Patologia não respiratória com critério de internamento e RT-PCR para SARS -CoV-2 detetável;

- Grupo IV. Doentes paucissintomáticos/assintomáticos institucionalizados em residência sénior com RT-PCR para SARS-CoV-2 detetável (Tabela 2).

Excluíram-se da análise os doentes inicialmente suspeitos de terem COVID-19 nos quais não houve confirmação laboratorial por RT-PCR, durante o internamento e o diagnóstico final encontrado foi outro.

Foi considerado o dia do início dos sintomas como sendo o primeiro dia da doença.

Os dados foram coletados do processo clínico eletrónico e da base de dados criada pela EMD para registo de parâmetros protocolados para seguimento dos doentes internados no IDNC. Incluíram informação demo- gráfica, comorbilidades, terapêutica de ambulatório, resultados dos exames complementares (laboratoriais, eletrocardiográficos e imagiológicos), opções terapêuticas de acordo com o protocolo interno, ocorrência de ventilação mecânica e necessidade de oxigenioterapia, diagnósticos secundários e resultados (incluindo demora média, destino na alta, readmissão e mortalidade). Utilizou-se o índice de comorbilidades de Charlson para quantificar o peso das comorbilidades e prever a sobrevida (um score superior a 6 corresponde a $0 \%$ de sobrevida a 10 anos. ${ }^{18-22}$

\section{RESULTADOS}

Foram incluídos um total de 44 doentes (média de idades global de 67 anos; nos homens, 63 anos e, nas muIheres, 70,5 anos; intervalo de idades entre 29 e 94 anos); 52,3\% eram homens (Tabela 2).

Ocorreu um pico de internamentos no dia 7 de abril, tendo o maior número de doentes sido admitido nas primeiras três semanas (Fig. 1).

Os doentes distribuíram-se por 4 grupos consoante a forma de apresentação: no Grupo I - 21 doentes (47,7\%), no Grupo II - 12 doentes (27,3\%), no Grupo III - 8 doentes $(18,2 \%)$ e no Grupo IV - 3 doentes (6,8\%) (Tabela 2).

Relativamente à proveniência dos doentes, 36 (81,8\%) vieram do domicílio, $5(11,4 \%)$ de residência sénior, e 3 (6,8\%) vieram transferidos do HCD (Tabela 2).

Das comorbilidades conhecidas como fator de risco para doença COVID-19 mais grave, neste grupo de doentes as mais frequentes foram a idade > 65 anos (23; 52,2\%), a hipertensão arterial (26; 59\%), doença respiratória crónica (7; 15,9\%), obesidade (7; 15,9\%), neoplasia maligna ativa $(6 ; 13,6 \%)$, diabetes $(5 ; 11,4 \%)$, cardiopatia isquémica (5; 11,4\%), insuficiência cardíaca (3; 6,8\%), imunossupressão (3; 6,8\%) (Tabela 2).23,24 
TABELA 2. Características dos doentes.

\begin{tabular}{|c|c|}
\hline & $N^{\circ} .(\%)$ \\
\hline Total Doentes & 44 \\
\hline \multicolumn{2}{|l|}{ PROVENIÊNCIA } \\
\hline Domicílio & $36(81,8)$ \\
\hline Residência Sénior & $5(11,4)$ \\
\hline $\mathrm{HCD}$ & $3(6,8)$ \\
\hline \multicolumn{2}{|l|}{ MULHER/HOMEM } \\
\hline Total & $21(47,7) / 23(52,3)$ \\
\hline Média de idades - anos & $70,5 / 63$ \\
\hline \multicolumn{2}{|l|}{ SINTOMAS NAADMISSÃO } \\
\hline Tosse & $24(54,5)$ \\
\hline Febre & $19(43,2)$ \\
\hline Dispneia & $11(25,0)$ \\
\hline Mialgias & $8(18,2)$ \\
\hline Toracalgia & $7(15,9)$ \\
\hline Diarreia & $4(9,0)$ \\
\hline Cansaço & $4(9,0)$ \\
\hline Odinofagia & $4(9,0)$ \\
\hline \multicolumn{2}{|l|}{ APRESENTAÇÃO CLÍNICA } \\
\hline Grupo I & $21(47,7)$ \\
\hline Grupo II & $12(27,3)$ \\
\hline Grupo III & $8(18,2)$ \\
\hline Grupo IV & $3(6,8)$ \\
\hline \multicolumn{2}{|l|}{ COMORBILIDADES } \\
\hline Hipertensão arterial & $26(59,0)$ \\
\hline Doença respiratória crónica & $7(15,9)$ \\
\hline Dislipidemia & $7(15,9)$ \\
\hline Obesidade & $7(15,9)$ \\
\hline Neoplasia maligna ativa & $6(13,6)$ \\
\hline Diabetes mellitus tipo 2 & $5(11,4)$ \\
\hline Cardiopatia isquémica & $5(11,4)$ \\
\hline Tabagismo & $4(9,1)$ \\
\hline Insuficiência cardíaca & $3(6,8)$ \\
\hline Imunossupressão & $3(6,8)$ \\
\hline Fibrilhação auricular & $3(6,8)$ \\
\hline Demência & $2(4,5)$ \\
\hline Doença renal & $1(2,3)$ \\
\hline Depressão & $1(2,3)$ \\
\hline SAOS & $1(2,3)$ \\
\hline Índice de Comorbilidades de Charlson-média & 3,6 \\
\hline $\begin{array}{l}\text { Número de medicamentos } \\
\text { de ambulatório - média }\end{array}$ & 5,3 \\
\hline \multicolumn{2}{|l|}{ RT PCR SARS-CoV-2 } \\
\hline Média de testes por doente & 2,95 \\
\hline \multicolumn{2}{|l|}{ Resultado à entrada / saída: } \\
\hline Detetável & $26 / 10$ \\
\hline Não detetável & $15 / 29$ \\
\hline Indeterminado & $3 / 3$ \\
\hline Não aplicável & $\mathrm{O} / 2$ \\
\hline \multicolumn{2}{|l|}{ SEROLOGIA CORONAVÍRUS-19 } \\
\hline Número de testes & $14(31,8)$ \\
\hline $\lg M(0 />0<1 />1)$ & $0 / 12 / 2$ \\
\hline $\operatorname{lgG}(0 />0<1 />1)$ & $7 / 4 / 3$ \\
\hline \multicolumn{2}{|l|}{ PADRÃO IMAGIOLÓGICO NA TC-T } \\
\hline Localização "típica” & $30(68,2)$ \\
\hline Localização "atípica" & $2(4,5)$ \\
\hline Não sugestivo & $3(6,8)$ \\
\hline Sem pneumonia & $9(20,5)$ \\
\hline
\end{tabular}

\begin{tabular}{|c|c|}
\hline & $\mathrm{N}^{\circ} .(\%)$ \\
\hline \multicolumn{2}{|l|}{ TEMPO DE SINTOMAS - DIAS } \\
\hline Até ao diagnóstico & 7,43 \\
\hline Até às complicações & 13,5 \\
\hline MEWS médio & 1,18 \\
\hline \multicolumn{2}{|l|}{ DIAGNÓSTICOS PRINCIPAIS } \\
\hline Pneumonia & $33(75,0)$ \\
\hline Traqueobronquite & $2(4,5)$ \\
\hline Hemorragia digestiva & $2(4,5)$ \\
\hline Cistite hemorrágica & $1(2,3)$ \\
\hline Colecistite aguda & $1(2,3)$ \\
\hline Diverticulite & $1(2,3)$ \\
\hline Osteoporose fraturária & $1(2,3)$ \\
\hline Espondilodiscite & $1(2,3)$ \\
\hline Gastroenterite a SARS-CoV-2 & $1(2,3)$ \\
\hline Colangite & $1(2,3)$ \\
\hline \multicolumn{2}{|l|}{ DIAGNÓSTICOS SECUNDÁRIOS } \\
\hline Insuficiência respiratória & $32(72,7)$ \\
\hline Sobreinfeção bacteriana & $10(22,7)$ \\
\hline ITU & $4(9,1)$ \\
\hline Ventilação mecânica & $2(4,5)$ \\
\hline Insuficiência cardíaca descompensada & $2(4,5)$ \\
\hline Vertebroplastia & $2(4,5)$ \\
\hline FA rápida & $1(2,3)$ \\
\hline Anemia aguda & $1(2,3)$ \\
\hline Neoplasia do pulmão & $1(2,3)$ \\
\hline Osteoporose fraturária & $1(2,3)$ \\
\hline Fractura traumática do olecrânio & $1(2,3)$ \\
\hline Síndrome de Cushing & $1(2,3)$ \\
\hline Rabdomiolise & $1(2,3)$ \\
\hline Crise hipertensiva & $1(2,3)$ \\
\hline Insuficiência renal aguda & $1(2,3)$ \\
\hline Laminotomia & $1(2,3)$ \\
\hline Orquiepididimite & $1(2,3)$ \\
\hline Gripe A & $1(2,3)$ \\
\hline \multicolumn{2}{|l|}{ TERAPÊUTICAANTIMICROBIANA } \\
\hline $\mathrm{HCQ}+\mathrm{AZT}$ & $30(68,2)$ \\
\hline $\mathrm{HCQ}$ & $2(4,5)$ \\
\hline Sem terapêutica antimicrobiana & $11(25,0)$ \\
\hline HCQ+Lopinavir & $1(2,3)$ \\
\hline \multicolumn{2}{|l|}{ TEMPO MÉDIO DE TRATAMENTO - DIAS } \\
\hline $\mathrm{HCQ}$ & 7,06 \\
\hline $\mathrm{AZT}$ & 5,06 \\
\hline Lopinavir+ Ritonavir & 5 \\
\hline \multicolumn{2}{|l|}{ OUTRASTERAPÊUTICAS } \\
\hline Corticoterapia sistémica & $3(6,8)$ \\
\hline Oxigenioterapia & $32(72,7)$ \\
\hline Reinternamento & $1(2,3)$ \\
\hline \multicolumn{2}{|l|}{ DESTINO } \\
\hline Domicílio & 36 \\
\hline Lar & 5 \\
\hline HCD & 3 \\
\hline Média de Internamento - dias & 10 \\
\hline Mortalidade & $1,0(2,3)$ \\
\hline
\end{tabular}


A média do índice de comorbilidades de Charlson foi de 3,6 (índices variando entre 0 e 12) (Tabela 2) - para calcular o prognóstico a 10 anos.

Apenas sete doentes (16\%) não faziam qualquer terapêutica prévia. A média de medicamentos de ambulatório nos restantes foi de 5,3 (variação entre 1 e 16). Dos doentes hipertensos, 20 (77\%) faziam uso de inibidores da enzima de conversão da angiotensina ou antagonistas dos recetores da angiotensina II (Tabela 2).
Na admissão, os sintomas mais referidos foram: tosse (24; 54,5\%), febre (19; 43,2\%), dispneia (11; 25\%), mialgias (8; 18,2\%), toracalgia (7; 15,9\%), diarreia (4; 9\%), cansaço (4; 9\%) e odinofagia (4; 9\%). O tempo médio de sintomas até ao diagnóstico foi de 7,43 dias (entre 1 e 15 dias) (Tabela 2).

O primeiro teste por RT-PCR para COVID-19 foi positivo em 26 doentes (59,1\%), negativo em 15 doentes (34,1\%) e indeterminado em 3 doentes (6,8\%); 6 dos doentes inicialmente negativos vieram positivos num

TABELA 3. Protocolo de tratamento da COVID-19 no internamento do doente não crítico (IDNC) - Medicina Interna.

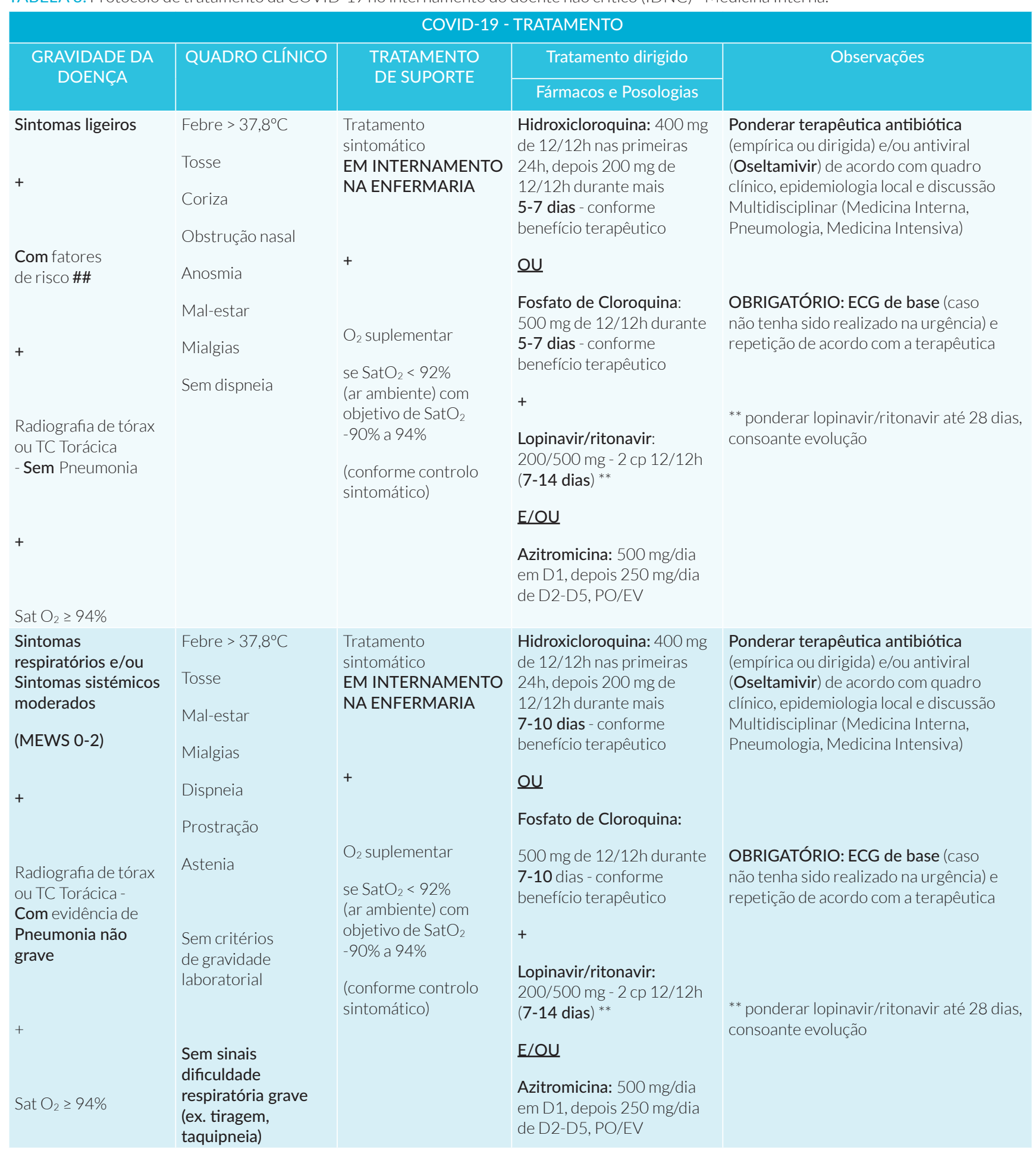


TABELA 3. Protocolo de tratamento da COVID-19 no internamento do doente não crítico (IDNC) - Medicina Interna. (cont.)

\begin{tabular}{|c|c|c|c|c|}
\hline \multicolumn{5}{|c|}{ COVID-19 - TRATAMENTO } \\
\hline $\begin{array}{l}\text { GRAVIDADE DA } \\
\text { DOENÇA }\end{array}$ & QUADRO CLÍNICO & $\begin{array}{c}\text { TRATAMENTO } \\
\text { DE SUPORTE }\end{array}$ & $\begin{array}{c}\text { Tratamento dirigido } \\
\text { Fármacos e Posologias }\end{array}$ & Observações \\
\hline 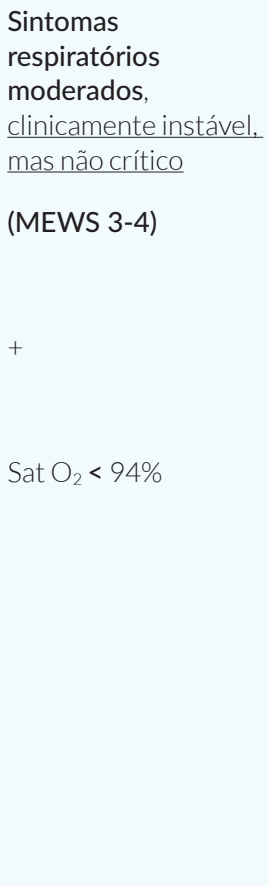 & $\begin{array}{l}\text { Dispneia moderada } \\
\text { Frequência } \\
\text { respiratória elevada } \\
\mathrm{SpO}_{2} \text { periférica } \\
\text { baixa ou Alterações } \\
\text { gasimétricas } \\
\text { Doente ainda } \\
\text { não crítico e sem } \\
\text { sinais de alarme } \\
\text { (falência respiratória } \\
\text { grave, dificuldade } \\
\text { respiratória grave, } \\
\text { perturbação } \\
\text { da consciência, } \\
\text { hipotensão ou } \\
\text { choque) }\end{array}$ & $\begin{array}{l}\text { Tratamento } \\
\text { sintomático e } \\
\text { internamento } \\
\text { em CUIDADOS } \\
\text { INTERMÉDIOS } \\
\text { (sempre que possível) } \\
\\
+ \\
\mathrm{O}_{2} \text { suplementar } \\
\text { se SatO }<92 \% \\
\text { (ar ambiente) com } \\
\text { objetivo de SatO } 2 \\
\text {-90\% a 94\% } \\
\text { (conforme controlo } \\
\text { sintomático) }\end{array}$ & $\begin{array}{l}\text { Idem ao estádio prévio - e } \\
\text { de acordo com Protocolo } \\
\text { da UCI }\end{array}$ & 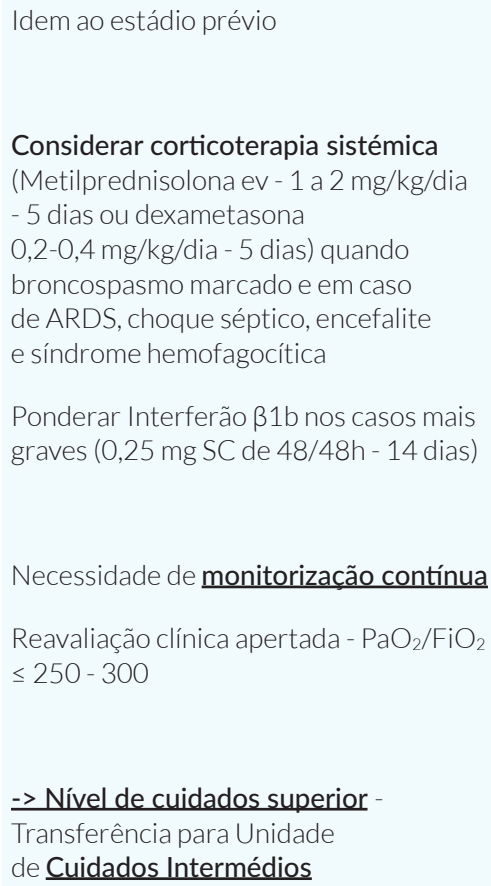 \\
\hline
\end{tabular}

\#\# Idade $\geq 65$ anos, patologia cardiovascular crónica (hipertensão arterial, cardiopatia isquémica, insuficiência cardíaca, doença renal crónica, doença vascular cerebral, taquidisritmia), patologia respiratória crónica (doença pulmonar obstrutiva crónica, asma mal controlada, bronquiectasias), diabetes mellitus, neoplasia maligna ativa, obesidade (índice de massa corporal $>30 \mathrm{~kg} / \mathrm{cm}^{2}$ ), imunossupressão.

teste subsequente, perfazendo um total de 32 doentes (72,7\%) cujo diagnóstico se confirmou laboratorialmente. E em média foram realizados 2,75 testes RT-PCR por doente (Tabela 2).

Todos os doentes suspeitos, mas não confirmados por teste RT-PCR, no momento da alta repetiram este teste PCR e realizaram serologias, havendo a confirmação adicional em um doente para COVID-19 por apresentar IgM e IgG positivos, aumentando para 33 (75\%) o total de doentes com confirmação laboratorial (Tabela 2). ${ }^{12}$

Todos os doentes com clínica respiratória (35; 79,5\%) realizaram tomografia computorizada torácica (TC-T) sendo encontrados diversos padrões imagiológicos já descritos na literatura como infiltrados em vidro despolido (32; 72,7\%) com distribuição maioritariamente bilateral, periférica, posterior e nos lobos inferiores, alguns destes também com padrão "em mosaico", bandas fibróticas e consolidação periférica. Em três doentes (6,8\%), o padrão imagiológico da pneumopatia não era sugestivo, apesar de terem RT-PCR detetável para SARS$-\mathrm{CoV}-2 .{ }^{14-17}$

Realizaram-se eletrocardiogramas seriados para monitorizar o potencial efeito secundário cardíaco dos fármacos antimicrobianos adotados. Mediu-se o inter- valo QTc no início e durante o período de administração destas terapêuticas, não tendo havido prolongamentos significativos do QT que obrigassem a suspender estes fármacos. O QTc médio inicial foi de 424 ms (variando entre 308 e 488) e, sob terapêutica, o QTc médio foi de 422 (variando entre 375 e 479).

O protocolo de intervenção terapêutica antimicrobiana dirigida incluiu hidroxicloroquina associada a azitromicina ( $\mathrm{HCQ}+\mathrm{AZT}$ ) em 30 doentes $(68,2 \%)$, hidroxicloroquina em monoterapia em dois doentes (4,5\%) e hidroxicloroquina associada a lopinavir-ritonavir em um doente (2,3\%). Não houve critérios para intervenção terapêutica em 11 doentes (25\%).

O tempo médio de tratamento com HCQ foi de 7,1 dias, com AZT de 5,1 dias e com lopinavir-ritonavir de 5 dias.

Em três doentes (6,8\%) introduziu-se corticoterapia sistémica e em 32 (72,7\%) oxigénio suplementar.

A coinfeção respiratória ocorreu por vírus Influenza A num doente $(2,3 \%)$ e presumivelmente por microrganismo bacteriano em 10 doentes (22,7\%).

Houve agravamento clínico significativo em quatro doentes (9,1\%), num deles ocorrendo o óbito e em três $(6,8 \%)$ houve necessidade de escalar cuidados para uma Unidade de Cuidados Intensivos (UCI), dois no HCIS e 
um para hospital público. Estes doentes da UCI do HCIS necessitaram de ventilação mecânica invasiva com um tempo médio de 5 dias. $\bigcirc$ tempo médio de sintomas até este agravamento foi de 13,5 dias (Tabela 2).

Os diagnósticos secundários mais frequentes foram: insuficiência respiratória em 32 doentes (72,7\%), com necessidade ventilação mecânica em 2 (4,5\%); coinfeção respiratória bacteriana em 10 (22,7\%); infeção do trato urinário (ITU) em 4 (9,1\%) (Tabela 2).

A demora média de internamento foi de 10 dias. Dos doentes que sobreviveram, o destino na alta foi em 35 para o domicílio, cinco para residência sénior (local de proveniência) e três transferências para hospital público (perdendo-se o seguimento) (Tabela 2).

Não houve readmissões por COVID-19, mas ocorreu um reinternamento por patologia abdominal aguda num doente ainda com RT-PCR detetável.

Registou-se um óbito num doente do género feminino, correspondendo a uma mortalidade de 2,3\% (Tabela 2).

\section{DISCUSSÃO}

A casuística apresentada representa o primeiro grupo de doentes não críticos internados com infeção por SARS-CoV-2 na Rede CUF da Região de Lisboa (no HCIS).

A média de idades foi superior a 65 anos (sendo esta faixa etária a de pior prognóstico nesta doença), a maioria do género masculino. Apesar da hipertensão arterial ter sido o fator de risco mais prevalente, esta população apresentou muitos dos restantes fatores de risco para doença grave e mau prognóstico já identificados em estudos publicados. ${ }^{20-23}$

Ocorreram casos de doentes com RT-PCR não detetável em que a TC-T colocou a hipótese diagnóstica de COVID-19, alguns deles posteriormente confirmados por novos testes PCR e/ou serológicos, mantendo-se o diagnóstico presuntivo em 25\%, na falta de testes laboratoriais com elevada especificidade e perante uma apresentação clínica e laboratorial sugestiva. A TC-T demonstrou-se crucial para o diagnóstico nesta população.

Em 75\% dos doentes instituiu-se terapêutica antimicrobiana "antiviral" segundo o protocolo, com tolerância e aparente eficácia, embora não existisse um grupo controlo.

Dos três doentes transferidos para UCl, os 2 que permaneceram no HCIS necessitaram de VMI e regressaram ao IDNC, tendo posteriormente alta. O doente transferido para o hospital público perdeu-se para o seguimento.
A mortalidade intra-hospitalar foi baixa (2,3\%) embora existisse um índice de comorbilidades de Charlson médio de 3,6 e se tratasse de uma população polimedicada.

O facto de a amostra ser pequena e se tratar de uma análise retrospetiva, condiciona a interpretação destes resultados.

\section{CONCLUSÃO}

Descreve-se a experiência vivida na abordagem da COVID-19,espelhandooimensodesafioquefoitrataruma doença até agora desconhecida para esta equipa médica. Esta série de casos descreve as características da população de doentes não críticos com infeção pelo novo coronavírus, internados a cargo da Medicina Interna no HCIS na fase inicial do surto pandémico em Portugal.

Aplicaram-se os protocolos de avaliação e atuação especialmente criados para esta situação, pela equipa médica dedicada, à luz do conhecimento então existente.

A vigilância apertada destes doentes e a existência de uma equipa de Medicina dedicada (24 horas/7 dias por semana) capaz de detetar e adequar precocemente os cuidados, terá seguramente contribuído de forma decisiva para os bons resultados alcançados.

Perante as incertezas sobre a eficácia das atuais opções terapêuticas, mas sendo reconhecido que populações mais idosas e com multimorbilidade, como a apresentada, têm pior prognóstico, os resultados obtidos foram muito satisfatórios.

\section{AGRADECIMENTOS/ ACKNOWLEDGEMENTS}

Os Autores agradecem a todos os outros médicos que colaboraram no acompanhamento destes doentes:

Hernando Campos, Gustavo Carvalho, Luís Costa, Ferreira Gomes, Carolina Lalanda, Joaquim Santos Lima, Inês Mendes, Paula Mexia, Mariana Ramalho, Cepeda Ribeiro, Ricardo Ribeiro, Tetiana Shara.

\section{RESPONSABILIDADES ÉTICAS}

CONFLITOS DE INTERESSE: Os autores declaram a inexistência de conflitos de interesse na realização do presente trabalho.

FONTES DE FINANCIAMENTO: Não existiram fontes externas de financiamento para a realização deste artigo.

CONFIDENCIALIDADE DOS DADOS: Os autores declaram ter seguido os protocolos da sua instituição acerca da publicação dos dados de doentes. 
PROTEÇÃO DE PESSOAS E ANIMAIS: Os autores declaram que os procedimentos seguidos estavam de acordo com os regulamentos estabelecidos pelos responsáveis da Comissão de Investigação Clínica e Ética e de acordo com a Declaração de Helsínquia da Associação Médica Mundial.

PROVENIÊNCIA E REVISÃO POR PARES: Não comissionado; revisão externa por pares.

\section{ETHICAL DISCLOSURES}

CONFLICTS OF INTEREST: The authors have no conflicts of interest to declare.

FINANCING SUPPORT: This work has not received any contribution, grant or scholarship.

CONFIDENTIALITY OF DATA: The authors declare that they have followed the protocols of their work center on the publication of data from patients.

PROTECTION OF HUMAN AND ANIMAL SUBJECTS: The authors declare that the procedures followed were in accordance with the regulations of the relevant clinical research ethics committee and with those of the Code of Ethics of the World Medical Association (Declaration of Helsinki).

PROVENANCE AND PEER REVIEW: Not commissioned; externally peer reviewed.

\section{REFERÊNCIAS}

1. World Health Organization. Novel Coronavirus (2019-nCoV) situation report - 121 January 2020 [consultado Abril 2020] Disponivel em: https://www.who.int/emergencies/diseases/ novel-coronavirus-2019/situation-reports.

2. Direção Geral da Saúde. - COVID 19. [consultado abril 2020] Disponível em: https://covid19.min-saude.pt/wp-content/ uploads/2020/03/Atualiza\%C3\%A7\%C3\%A3-de-02032020 -1728.pdf.

3. Decreto do Presidente da República n. 14-A/2020 [consultado abril 2020] Disponível em: https://dre.pt/web/guest/ home/-/dre/130399862/details/maximized.

4. Direção Geral da Saúde. COVID 19. [consultado abril 2020] Disponível em: https://www.dgs.pt/directrizes-da-dgs/ normas-e-circulares-normativas/norma-n-0012020-de-16032020-pdf.aspx.

5. Coronavírus: Privados preparam-se para receber doentes. CUF ativa dois hospitais-in press 17 de março de 2020. [consultado abril 2020] Disponível em: https://www.publico.pt/2020/03/17/sociedade/noticia/coronavirus-privados-preparamse-receber-doentes-cuf-activa-dois-hospitais-1908227.

6. Gobierno de Espana - Ministerio de Sanidad - Documento técnico Manejo clínico del COVID-19: atención hospitalaria, 18 de mayo de 2020 [consultado maio 2020] Disponível em: https://www.mscbs.gob.es/profesionales/saludPublica/ccayes/alertasActual/nCov-China/documentos/Protocolo_manejo_clinico_ah_COVID-19.pdf.
7. Gautret P, Lagier JC, Parola P, Hoang VT, Meddeb L, Mailhe M, et al. Hydroxychloroquine and azithromycin as a treatment of COVID-19: results of an open-label non-randomized clinical trial. Int J Antimicrob Agents. 2020 (in press). doi:10.1016/j. ijantimicag.2020.105949.

8. Cortegiani A, Ingoglia G, Ippolito M, Giarratano A, Einav S. A systematic review on the efficacy and safety of chloroquine for the treatment of COVID-19. J Crit Care. 2020;57:279-83. doi: 10.1016/j.jcrc.2020.03.005.

9. INFARMED: Orientações de Acesso a Terapêuticas Experimentais no tratamento de COVID-19 - infeção pelo SARS-CoV-2. [consultado Abril 2020] Disponível em: https:// www.infarmed.pt/documents/15786/3584301/Orienta\%C3\%A7\%C3\%B5es+de+Acesso+a+Terap\%C3\%AAuticas+Experimentais+no+tratamento+de+COVID-19+-+infe\%C3\%A7\%C3\%A3o+pelo+SARS-CoV-2/c9595d6a-6a2f$-255 d-1 f 45-668 b 20 d b 0 e d 6$.

10. Sociedade Portuguesa de Cuidados Intensivos. Recomendações da Sociedade Portuguesa de Cuidados Intensivos para a Abordagem da COVID-19 em Medicina Intensiva. Lisboa: SPCI; 2020. [consultado abril 2020] Disponível em:https:// www.spci.pt/covid-19

11. Nicastri E, Petrosillo N, Bartoli TA, Lepore L, Mondi A, Palmieri F, et al. National Institute for the Infectious Diseases "L. Spallanzani", IRCCS. Recommendations for COVID-19 clinical management. Infect Dis Rep. 2020;12:8543. doi: 10.4081/ idr.2020.8543.

12. European Centre for Disease Prevention and Control. Laboratory support for COVID-19 in the EU/EEA. Testing for SARS-CoV-2 virus. [consultado abril 2020] Disponível em: https:// www.ecdc.europa.eu/en/novel-coronavirus/laboratory-support.

13. Subbe CP, Kruger M, Rutherford P, Gemmel L. Validation of a modified Early Warning Score in medical admissions. QJM. 2001;94:521-6. doi:10.1093/qjmed/94.10.521.

14. Shi H, Han X, Jiang N, Cao Y, Alwalid O, Gu J, et al. Radiological findings from 81 patients with COVID-19 pneumonia in Wuhan, China: a descriptive study. Lancet Infect Dis. 2020;20:425-34. doi:10.1016/S1473-3099(20)30086-4.

15. Salehi S, Abedi A, Balakrishnan S, Gholamrezanezhad A. Coronavirus Disease 2019 (COVID-19): A Systematic Review of Imaging Findings in 919 Patients. AJR Am J Roentgenol. 2020 (in press). doi:10.2214/AJR.20.23034.

16. British Society of Thoracic Imaging Statement and Guidance. COVID-19. [consultado Abril 2020] Disponível em: https:// www.bsti.org.uk/media/resources/files/BSTI_COVID-19_Radiology_Guidance_version_2_16.03.20.pdf.

17. Ye Z, Zhang Y, Wang Y, Huang Z, Song B. Chest CT manifestations of new coronavirus disease 2019 (COVID-19): a pictorial review. Eur Radiol. 2020 (in press). doi: 10.1007/s00330-02006801-0.

18. Charlson ME, Pompei P, Ales KL, MacKenzie CR. A New Method of Classifying Prognostic Comorbidity in Longitudinal Studies: Development and Validation J Chronic Dis. 1987;40:373-83. doi: 10.1016/0021-9681 (87)90171-8. online:https://pubmed.ncbi.nlm.nih.gov/3558716/.

19. Quan H, Li B, Couris CM, Fushimi K, Graham P, Hider P, et al. Updating and validating the Charlson comorbidity index and score for risk adjustment in hospital discharge abstracts using data from 6 countries. Am J Epidemiol. 2011;173:676-82. doi: 10.1093/aje/kwq433.

20. Richardson S, Hirsch JS, Narasimhan M, Crawford JM, McGinn T, Davidson KW, et al. Presenting Characteristics, Comorbidities, and Outcomes Among 5700 Patients Hospitalized With COVID-19 in the New York City Area. JAMA. 
2020;323:2052-9. doi:10.1001/jama.2020.6775. Erratum in: doi:10.1001/jama.2020.7681.

21. Kobayashi KI, Kaki T, Mizuno S, Kubo K, Komiya N, Otsu S. Clinical characteristics of patients with COVID-19 in Japan: a single-center case series. J Infect Dis. 2020 (in press). doi: 10.1093/infdis/jiaa244.

22. Bhatraju PK, Ghassemieh BJ, Nichols M, Kim R, Jerome KR, Nalla AK, et al. Covid-19 in Critically III Patients in the Seattle Region - Case Series. N Engl J Med. 2020;382:2012-22. doi: 10.1056/NEJMoa2004500.

23. Petrilli CM, Jones SA, Yang J, Rajagopalan H, O'Donnell L, Chernyak Y, et al. Factors associated with hospital admission and critical illness among 5279 people with coronavirus disease 2019 in New York City: prospective cohort study. BMJ. 2020 (in press). doi:10.1136/bmj.m1966.

24. Guan WJ, Liang WH, Zhao Y, Liang HR, Chen ZS, Li YM, et al. Comorbidity and its impact on 1590 patients with COVID-19 in China: a nationwide analysis Eur Respir J. 2020; 55: 2000547. doi: 10.1183/13993003. 00547-2020. 